\title{
Vagal tone regulates cardiac shunts during activity and at low temperatures in the South American rattlesnake, Crotalus durissus
}

\author{
Renato Filogonio $^{1,2}$ (1) $\cdot$ Tobias Wang ${ }^{2}$ Edwin W. Taylor ${ }^{1,3} \cdot$ Augusto S. Abe $^{1} \cdot$ \\ Cléo A. C. Leite ${ }^{4}$
}

Received: 2 February 2016 / Revised: 18 May 2016 / Accepted: 3 June 2016 / Published online: 13 June 2016

(C) Springer-Verlag Berlin Heidelberg 2016

\begin{abstract}
The undivided ventricle of non-crocodilian reptiles allows for intracardiac admixture of oxygen-poor and oxygen-rich blood returning via the atria from the systemic circuit and the lungs. The distribution of blood flow between the systemic and pulmonary circuits may vary, based on differences between systemic and pulmonary vascular conductances. The South American rattlesnake, Crotalus durissus, has a single pulmonary artery, innervated by the left vagus. Activity in this nerve controls pulmonary conductance so that left vagotomy abolishes this control. Experimental left vagotomy to abolish cardiac shunting had no effect on long-term survival and failed to identify a functional role in determining metabolic rate, growth or resistance to food deprivation. Accordingly, the present investigation sought to evaluate the extent to which cardiac shunt patterns are actively controlled during changes in body temperature and activity levels. We compared hemodynamic parameters between intact and left-vagotomized rattlesnakes held at different temperatures and subjected to enforced physical activity. Increased temperature and enforced activity raised heart rate, cardiac output,
\end{abstract}

Communicated by H. V. Carey.

Renato Filogonio

renatofilogonio@gmail.com

1 Department of Zoology, State University of São Paulo (UNESP), Rio Claro, SP, Brazil

2 Zoophysiology, Department of Bioscience, Aarhus University, 8000 Aarhus C, Denmark

3 School of Biosciences, University of Birmingham, Birmingham B15 2TT, UK

4 Department of Physiological Sciences, Federal University of São Carlos (UFSCar), São Carlos, SP, Brazil pulmonary and systemic blood flow in both groups, but net cardiac shunt was reversed in the vagotomized group at lower temperatures. We conclude that vagal control of pulmonary conductance is an active mechanism regulating cardiac shunts in $C$. durissus.

Keywords Reptiles · Snakes · Cardiac shunt · Vagus nerve $\cdot$ Arterial pressure $\cdot$ Blood flow $\cdot$ Vascular regulation

\section{Introduction}

The undivided ventricle of the non-crocodilian reptile heart enables variable proportions of cardiac output to bypass the systemic or pulmonary circulations, resulting in either left-to-right $(\mathrm{L}-\mathrm{R})$ or right-to-left $(\mathrm{R}-\mathrm{L})$ cardiac shunts (Wang et al. 2001). The direction and magnitude of the cardiac shunts affect arterial blood gases, and it has been suggested that active control of these shunts is as important as pulmonary ventilation in regulating arterial oxygen levels (Wang and Hicks 1996a; Wang et al. 1997). However, the functional role of cardiac shunts remains largely unresolved (Hicks and Wang 2012) and recent experimental evidence, based on chronic manipulation of cardiac shunt patterns in rattlesnakes, questions whether $\mathrm{R}-\mathrm{L}$ shunts influence metabolic regulation, measured as long-term changes in metabolic rate, growth and resistance to food deprivation (Leite et al. 2013, 2014). Similar conclusions have been reached on crocodilians where permanent ligature of the left aortic arch, which normally allows for R-L shunts, is without effects on growth, diving metabolism or respiratory patterns (Eme et al. 2009, 2010).

Despite failure to demonstrate a clear physiological role for cardiac shunting in these organisms, it has been shown 
that shunt patterns in turtles change consistently with metabolic rate. For instance, during activity, pulmonary vascular conductance $\left(G_{\text {pul }}\right)$ and blood flow $\left(\dot{Q}_{\text {pul }}\right)$ increase more than systemic blood flow $\left(\dot{Q}_{\text {sys }}\right)$ causing a reduction in net R-L shunts (Krosniunas and Hicks 2003; West et al. 1992). Similar hemodynamic changes occur during pulmonary ventilation (Wang and Hicks 1996b), hypoxia (Wang et al. 1997; Herman and Smatresk 1999) and when temperature increases (Galli et al. 2004).

It is clear that several mechanisms may influence cardiac shunt patterns. For amphibians, it was recently argued that the rise in L-R shunt at high cardiac output (CO) is mainly driven by inherent physical properties of the vascular system, where the high distensibility of the pulmonary circuit allows for increased pulmonary blood flow (Hillman et al. 2014; Kohl et al. 2013). In reptiles, activity in the vagal innervation of the pulmonary artery can massively reduce $G_{\text {pul }}$ and increased vagal tone can mediate large net R-L shunts (Burggren 1987; Luckhardt and Carlson 1921; Milsom et al. 1977; Taylor et al. 2009). Adrenergic control of systemic conductance $\left(G_{\text {sys }}\right)$ may alter blood flow relations (Hicks 1994; Galli et al. 2007), and many humoral factors such as nitric oxide (Crossley et al. 2000; Galli et al. 2005a), bradykinin (Galli et al. 2005b) and adenosine (Joyce and Wang 2014) have also been demonstrated to affect cardiac shunt patterns. Thus, as the relative importance of central regulation of cardiac shunt patterns through vagal innervation of the pulmonary artery remains uncertain, it is pertinent to re-evaluate whether the vagus accounts for significant changes in cardiac shunts to respond to alterations in metabolic demand in conscious organisms. This is a fundamental question in the current debate on whether or not the regulation of cardiac shunts provide adaptive advantages to reptiles (Hicks 2002).

Given that the persistence of R-L shunt leads to arterial blood desaturation, high metabolic demands should cause reduced $\mathrm{R}-\mathrm{L}$ shunts or even generate $\mathrm{L}-\mathrm{R}$ shunts (Hicks and Wang 2012). In the present study, we investigate whether the vagus actively regulates cardiac shunt patterns in South American rattlesnakes (Crotalus durissus Linnaeus 1758). This species possesses a typical reptilian heart (Jensen et al. 2010), but only the left branch of the vagus controls the smooth muscle of its single pulmonary artery (Taylor et al. 2009). Hence, unilateral left vagotomy abolishes the control of $G_{\text {pul }}$ without affecting regulation of heart rate $\left(f_{\mathrm{H}}\right)$, which is maintained via the right vagus (Leite et al. 2013; Taylor et al. 2009). We studied rattlesnakes with and without left vagotomy to verify whether cardiac shunts are actively regulated under different temperatures and activity.

\section{Materials and methods}

\section{Experimental animals}

Thirty-two South American rattlesnakes, Crotalus durissus $(1.2 \pm 0.1 \mathrm{~kg})$, were obtained from the Butantan Institute (São Paulo, Brazil) and transported to Universidade Estadual Paulista in Rio Claro (São Paulo, Brazil), where they were maintained in $0.5 \times 0.5 \times 0.5 \mathrm{~m}$ cages at $28 \pm 5^{\circ} \mathrm{C}$ on a natural light regime with free access to water. They were fed rodents approximately once a week, but food was withheld 15 days prior to experiments. All incisions were accompanied by subcutaneous injection of $2 \%$ Lidocaine (Pearson, São Paulo). At completion of the experimental protocol, snakes were euthanized by an intravenous overdose of lidocaine. All procedures were performed in accordance with the guidelines for animal experimentation (CEUA, 023/2011, UNESP, Rio Claro).

\section{Surgery and instrumentation}

The snakes were initially anesthetized with $\mathrm{CO}_{2}$ until righting reflexes disappeared (Wang et al. 1993) and intubated for mechanical ventilation with 1-4\% isoflurane in air, at a rate of 5 breaths $\min ^{-1}$ with a tidal volume of $30 \mathrm{ml} \mathrm{kg}^{-1}$. Snakes were then defanged and their mouth sutured with two lateral stitches to render them harmless during activity trials (see experimental protocol below). The left branch of the vagus nerve was exposed through a $2 \mathrm{~cm}$ rostro-caudal incision caudally from the 7th line of the ventral scales. Half of the experimental group $(n=15)$ had the left vagus sectioned by removal of $1-2 \mathrm{~cm}$ of the nerve, as previously described (Leite et al. 2013, 2014), whereas the other half $(n=17)$ underwent a sham operation. Following trial instrumentation, blood flows and pressures were measured in separate groups of snakes, to avoid excessive instrumentation of individual animals. Flows were measured on 20 snakes $(1.4 \pm 0.1 \mathrm{~kg}$ ), either intact or vagotomized (10 in each group), while pressures were measured on 12 snakes $(0.8 \pm 0.1 \mathrm{~kg} ; 6$ in each group $)$.

A $5 \mathrm{~cm}$ ventrolateral incision cranial to the heart provided access to the systemic and pulmonary arteries. For measurements of mean systemic pressure $\left(P_{\text {sys }}\right)$, a catheter was inserted occlusively into the vertebral artery and forwarded into the right aortic arch. Another catheter, for measurement of mean pulmonary pressure $\left(P_{\text {pul }}\right)$, was inserted occlusively into a branch of the pulmonary artery. Both catheters (PE50) contained heparinized saline $(100 \mathrm{IU} / \mathrm{ml})$ and were connected to Baxter Edward (model PX600, Irvine, CA, USA) disposable pressure transducers. Signals were amplified with an in-house 
built preamplifier and transducers were calibrated daily with a static water column. Blood flow was measured using probes $(2.0 \mathrm{RB}$ or $1.5 \mathrm{RB}$, Transonic Systems, Inc, NY, USA) placed around the left aortic arch or the pulmonary artery to record respective blood flows $\left(\dot{Q}_{\mathrm{LAo}}\right.$ and $\dot{Q}_{\text {pul }}$. Ultrasound gel was infused around each blood flow probe to enhance the signal. The probes were connected to a dual-channel blood flow meter (Transonic T206, Transonic Systems, Inc, NY, USA). Signals from pressure transducers and flow probes were recorded via a Biopac MP100 data acquisition system (Biopac Systems, Inc., Goleta, CA, USA) at a rate of 400 samples s $^{-1}$. After surgery, each animal was placed in a plastic box $30 \times 50 \times 10 \mathrm{~cm}(W \times L \times H)$ maintained within a temperature-controlled chamber at a range of experimental temperatures (see protocol).

\section{Experimental protocol}

Cardiovascular parameters were found to have stabilized $24 \mathrm{~h}$ after surgery held in any of the three experimental temperatures: 15,20 or $30{ }^{\circ} \mathrm{C}$. At the end of these equilibration periods, blood pressures or flows were recorded for several hours from each snake while it remained undisturbed and following $5 \mathrm{~min}$ of uninterrupted activity. Activity was enforced by handling the snake within the temperature-controlled chamber to entice movement and consisted in immobilizing the animal's head while the body freely moved in response to continuous manipulation. After $5 \mathrm{~min}$, snakes appeared fatigued as they no longer responded to handling. After each recording, a change in temperature was randomly assigned within the chamber and snakes were let to equilibrate to the new temperature for a further $24 \mathrm{~h}$, when the protocol was repeated.

\section{Calculation of blood flows, stroke volumes, vascular conductances and shunt}

Systemic blood flow $\left(\dot{Q}_{\text {sys }}\right)$ was calculated from $\dot{Q}_{\text {LAo }}$ using the pooled correction factor relating both flows as $\dot{Q}_{\text {sys }}=2.6 \times \dot{Q}_{\text {LAo }}$ (Filogonio et al. 2014). Cardiac output (CO) was calculated as the sum of $\dot{Q}_{\text {sys }}$ and $\dot{Q}_{\text {pul }} f_{\mathrm{H} w a s}$ derived from the pulsatile signals of either blood pressure or flow. Systemic and pulmonary stroke volumes $\left(V \mathrm{~s}_{\mathrm{sys}}\right.$ and $V \mathrm{~s}_{\text {pul }}$, respectively) were calculated from the integration of the area under the blood flow signal in systemic and pulmonary circulations, respectively. Total stroke volume $(V \mathrm{~s})$ was the sum of $V \mathrm{~s}_{\text {sys }}$ and $V \mathrm{~s}_{\text {pul: }}$ Vascular conductances $\left(G_{\text {sys }}\right.$ and $\left.G_{\text {pul }}\right)$ were calculated as $\dot{Q}_{\text {sys }} / P_{\text {sys }}$ and $\dot{Q}_{\text {pul }} / P_{\text {pul }}$, respectively, assuming that venous blood pressures could be neglected (Crossley et al. 1998; Galli et al. 2004, 2007). When the ratio $\dot{Q}_{\text {pul }} / \dot{Q}_{\text {sys }}$ was $>1$, this indicated an $\mathrm{L}-\mathrm{R}$ cardiac shunt while a ratio $<1$ indicated an $\mathrm{R}-\mathrm{L}$ shunt.

\section{Statistical analyses}

One-way ANOVA for repeated measurements, followed by a post hoc Student-Newman-Keuls test, was used to verify the effects of temperature within each experimental group: intact snakes either inactive or following a bout of activity, left-vagotomized snakes, inactive or following activity. $T$ tests were used to assess the effects of vagotomy on inactive or active animals at each temperature, and paired $T$ tests to assess the effects of activity within both intact and vagotomized groups, at each temperature. This statistical approach was chosen because our set of data had two repeated measure factors (temperature and activity) and one non-repeated measure factor (vagotomy), precluding us from using a three-way ANOVA design. For $G_{\text {sys }}$ and $G_{\text {pul }}$ and data derived from $\dot{Q}_{\mathrm{LAo}}$, variances of products and ratios were calculated as proposed by Goodman (1969) and Kempen and Vliet (2000). Corresponding nonparametric tests were used whenever homoscedasticity or normality assumptions were not met. The assumption of sphericity was met for all repeated measure tests. A significance level was assigned at $95 \%$ probability $(P<0.05)$ in all cases. Data are presented as mean $\pm \mathrm{SD}$.

\section{Results}

\section{Effects of temperature change in intact snakes}

Heart rate and $\mathrm{CO}$ increased with temperature (Fig. 1a, c). $V \mathrm{~s}_{\text {sys }}$ decreased between 20 and $30{ }^{\circ} \mathrm{C}$, although neither $V \mathrm{~s}$ nor $V \mathrm{~s}_{\text {pul }}$ was affected (Table 1). Both $P_{\text {sys }}$ and $\dot{Q}_{\text {sys }}$ rose proportionally from 15 to $30{ }^{\circ} \mathrm{C}$ (Table 1; Fig. 1e); thus, $G_{\text {sys }}$ remained unchanged (Fig. 2). In contrast, $P_{\text {pul }}$ was unaffected by temperature (Table 1), and the threefold elevation of $\dot{Q}_{\text {pul }}$ between 15 and $30{ }^{\circ} \mathrm{C}$ (Fig. $1 \mathrm{~g}$ ) was mediated by a significant rise in $G_{\text {pul }}$ (Fig. 2a). Despite this differential regulation of $G_{\text {pul }}$ and $G_{\text {sys }}$, the R-L shunt was unaffected (Fig. 3).

\section{Cardiovascular responses to activity in intact snakes}

Both $\mathrm{CO}$ and $f_{\mathrm{H}}$ increased during activity at all temperatures (Fig. 1a), but $V \mathrm{~s}$ increased only at $15{ }^{\circ} \mathrm{C}$ (Table 1). Although $P_{\text {sys }}$ increased (Table 1$), G_{\text {sys }}$ was only affected at high temperatures (Fig. 2), such that $\dot{Q}_{\text {sys }}$ rose by $80 \%$ at $30{ }^{\circ} \mathrm{C}$, but did not change at the lower temperatures (Fig. 1). The rise in $\dot{Q}_{\text {sys }}$ was due to tachycardia, since $V \mathrm{~s}_{\mathrm{sys}}$ did not change (Table 1). $P_{\text {pul }}$ increased during activity at $30{ }^{\circ} \mathrm{C}$ (Table 1$)$, whereas $G_{\text {pul }}$ increased threefold at $15{ }^{\circ} \mathrm{C}$ and maintained very similar values at all temperatures (Fig. 2). Consequently, $\dot{Q}_{\text {pul }}$ was consistently higher than inactive values (Fig. $1 \mathrm{~g}$ ). $V \mathrm{~s}_{\text {pul }}$ did not change at 
- A - Inactive
- - Active
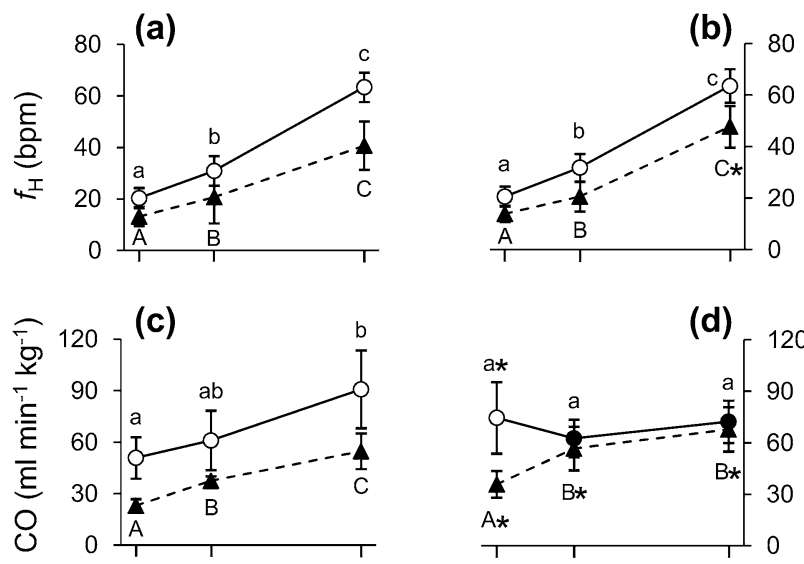

(e)
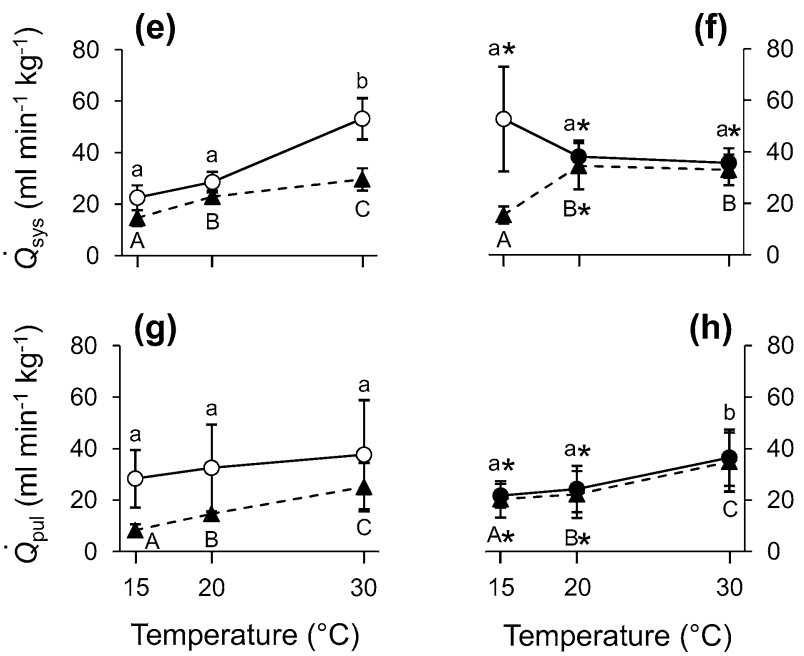

Fig. 1 Effects of temperature on either intact $(\mathbf{a}, \mathbf{c}, \mathbf{e}, \mathbf{g})$ or left-vagotomized (b, d, f, h) rattlesnakes (Crotalus durissus), inactive (triangle) or during activity (circle). Variables are: heart rate $\left(f_{\mathrm{H}}\right)$, cardiac output (CO), systemic blood flow ( $\left.\dot{Q}_{\text {sys }}\right)$ and pulmonary blood flow $\left(\dot{Q}_{\text {pul }}\right)$. Different capital letters indicate differences due to temperature change within inactive groups; different small letters indicate differences due to temperature change within active groups; open symbols indicate significant differences between the mean values from active and inactive snakes; an asterisk indicates an effect of left vagotomy. Values are mean \pm SD. Statistical significance was $P<0.05$. Sample sizes were: intact and inactive, $n=10$; intact and active, $n=9$; vagotomized and inactive, $n=10$; vagotomized and active, $n=9$

$30{ }^{\circ} \mathrm{C}$, but increased at lower temperatures (Table 1). L-R shunt decreased (Fig. 3) as $\dot{Q}_{\text {sys }}$ increased (Fig. 1e) and $\dot{Q}_{\text {pul }}$ remained stable (Fig. 1g).

\section{Effect of left vagotomy in inactive snakes}

The lack of control of pulmonary artery vasoconstriction in left-vagotomized snakes did not affect $f_{\mathrm{H}}$ except for a $17 \%$ rise at $30^{\circ} \mathrm{C}$ (Fig. 1b), but $\mathrm{CO}$ increased at all temperatures (Fig. 1d). $V$ s rose at 15 and $20{ }^{\circ} \mathrm{C}$ but decreased at $30{ }^{\circ} \mathrm{C}$, when it was similar to intact snakes (Table 1). Increased $V \mathrm{~s}$ and $\mathrm{CO}$ related to higher $V \mathrm{~s}_{\mathrm{pul}}$, as $V \mathrm{~s}_{\mathrm{sys}}$ was unaltered (Table 1). $P_{\text {pul }}$ increased at $30{ }^{\circ} \mathrm{C}$ and $P_{\text {sys }}$ was unaffected (Table 1).

$G_{\text {pul }}$ increased compared to intact snakes at $15{ }^{\circ} \mathrm{C}$, but remained constant with changes in temperature, whereas $G_{\text {sys }}$ was unaltered at all temperatures (Fig. 2). $\dot{Q}_{\text {sys }}$ was similar to intact animals at 15 and $30{ }^{\circ} \mathrm{C}$ (Fig. 1f), and $\dot{Q}_{\text {pul }}$ increased at 15 and $20{ }^{\circ} \mathrm{C}$ (Fig. 1h). Thus, vagotomy elicited an L-R shunt that reduced with temperature (Fig. 3).

\section{Cardiovascular responses of left-vagotomized snakes to activity}

In the vagotomized group, exercise tachycardia was similar to intact animals (Fig. 1b). The increase in $f_{\mathrm{H}}$ with temperature was matched by a reduction in $V \mathrm{~s}$ (Table 1), such that $\mathrm{CO}$ increased with activity at $15{ }^{\circ} \mathrm{C}$, but remained unchanged at 20 and $30^{\circ} \mathrm{C}$ (Fig. 1d). $P_{\text {sys }}$ in active vagotomized snakes was identical to those recorded in intact animals, whereas $P_{\text {pul }}$ was higher than in intact animals at $30{ }^{\circ} \mathrm{C}$ (Table 1). Both $P_{\text {sys }}$ and $P_{\text {pul }}$ diverged from inactive left-vagotomized values only at $30{ }^{\circ} \mathrm{C}$ (Table 1 ). The constant $G_{\text {pul }}$ was similar to that presented by active intact snakes (Fig. 2). $G_{\text {sys }}$ increased 2.6-fold compared to inactive vagotomized snakes at $15{ }^{\circ} \mathrm{C}$, but drastically decreased with temperature (61\%, see Fig. 2). This is the inverse hemodynamic alteration to that observed in active intact snakes (Figs. 3, 4).

\section{Discussion}

\section{Critique of the method}

It is important to note that the methods used to calculate variances (Goodman 1969; Kempen and Vliet 2000) are predicted to inflate the apparent standard deviation. However, we opted to calculate conductances using pressures and flows obtained from different individuals to reduce the stress imposed on each individual animal by insertion of probes (two cannulae or two blood flow probes placed in central vessels). Nevertheless, the qualitative patterns we found are in accordance with previous studies in $C$. durissus, with an increase of $G_{\text {pul }}$ and slight decrease of $G_{\text {sys }}$ with injected epinephrine (Galli et al. 2005a, 2007). Also, the reported values for mean arterial pressures and flows are in accordance with previous studies (Galli et al. 2005a, b, 2007; Leite et al. 2013; Taylor et al. 2009). 
Table 1 Effects of temperature change $\left(15,20\right.$ or $\left.30^{\circ} \mathrm{C}\right)$, activity (inactive or active) and vagotomy (intact or vagotomized) on mean blood pressures and stroke volumes $($ mean $\pm \mathrm{SD})$ of rattlesnakes

\begin{tabular}{|c|c|c|c|c|c|}
\hline Treatment & $P_{\text {sys }}(\mathrm{kPa})$ & $P_{\text {pul }}(\mathrm{kPa})$ & $V \mathrm{~s}\left(\mathrm{ml} \mathrm{kg}^{-1}\right)$ & $V \mathrm{~s}_{\mathrm{sys}}\left(\mathrm{ml} \mathrm{kg}^{-1}\right)$ & $V \mathrm{~s}_{\text {pul }}\left(\mathrm{ml} \mathrm{kg}^{-1}\right)$ \\
\hline \multicolumn{6}{|l|}{ Intact } \\
\hline \multicolumn{6}{|l|}{ Inactive } \\
\hline $15^{\circ} \mathrm{C}$ & $2.6 \pm 0.2^{\mathrm{a}}$ & $2.2 \pm 0.2^{\mathrm{a}}$ & $1.7 \pm 0.4^{\mathrm{a}}$ & $1.1 \pm 0.4^{\mathrm{a}}$ & $0.6 \pm 0.1^{\mathrm{a}}$ \\
\hline $20^{\circ} \mathrm{C}$ & $3.5 \pm 0.2^{\mathrm{ab}}$ & $2.6 \pm 0.2^{\mathrm{a}}$ & $1.7 \pm 0.6^{\mathrm{a}}$ & $1.1 \pm 0.6^{\mathrm{a}}$ & $0.6 \pm 0.1^{\mathrm{a}}$ \\
\hline $30^{\circ} \mathrm{C}$ & $4.4 \pm 0.5^{\mathrm{b}}$ & $2.3 \pm 0.2^{\mathrm{a}}$ & $1.3 \pm 0.3^{\mathrm{a}}$ & $0.7 \pm 0.2^{\mathrm{b}}$ & $0.6 \pm 0.1^{\mathrm{a}}$ \\
\hline \multicolumn{6}{|l|}{ Active } \\
\hline $15^{\circ} \mathrm{C}$ & $4.0 \pm 0.4^{\mathrm{a} *}$ & $2.9 \pm 0.3^{\mathrm{a}}$ & $2.3 \pm 0.5^{\mathrm{a} *}$ & $1.1 \pm 0.3^{\mathrm{a}}$ & $1.2 \pm 0.2^{\mathrm{a} *}$ \\
\hline $20^{\circ} \mathrm{C}$ & $4.6 \pm 0.2^{\mathrm{a} *}$ & $3.2 \pm 0.2^{\mathrm{a}}$ & $1.8 \pm 0.5^{\mathrm{ab}}$ & $0.9 \pm 0.2^{\mathrm{ab}}$ & $0.9 \pm 0.2^{\mathrm{b} *}$ \\
\hline $30^{\circ} \mathrm{C}$ & $6.0 \pm 0.5^{\mathrm{b} *}$ & $4.0 \pm 0.3^{\mathrm{b} *}$ & $1.4 \pm 0.3^{b}$ & $0.8 \pm 0.1^{\mathrm{b}}$ & $0.6 \pm 0.1^{\mathrm{c}}$ \\
\hline \multicolumn{6}{|c|}{ Vagotomized } \\
\hline \multicolumn{6}{|l|}{ Inactive } \\
\hline $15^{\circ} \mathrm{C}$ & $3.2 \pm 0.5^{\mathrm{a}}$ & $2.9 \pm 0.4^{\mathrm{a}}$ & $2.4 \pm 0.5^{\mathrm{a}}$ & $1.1 \pm 0.3^{\mathrm{a}}$ & $1.3 \pm 0.1^{\mathrm{a}}$ \\
\hline $20^{\circ} \mathrm{C}$ & $4.2 \pm 0.5^{\mathrm{a}}$ & $3.3 \pm 0.5^{\mathrm{a}}$ & $2.6 \pm 0.7^{a}$ & $1.7 \pm 0.6^{\mathrm{b}}$ & $0.9 \pm 0.2^{b}$ \\
\hline $30{ }^{\circ} \mathrm{C}$ & $4.6 \pm 0.3^{\mathrm{a}}$ & $3.6 \pm 0.3^{b}$ & $1.4 \pm 0.3^{b}$ & $0.7 \pm 0.2^{\mathrm{c}}$ & $0.7 \pm 0.1^{\mathrm{c}}$ \\
\hline \multicolumn{6}{|l|}{ Active } \\
\hline $15^{\circ} \mathrm{C}$ & $3.6 \pm 0.3^{\mathrm{a}}$ & $3.2 \pm 0.3^{\mathrm{a}}$ & $3.5 \pm 1.1^{a *}$ & $2.6 \pm 1.1^{a} *$ & $0.9 \pm 0.1^{\mathrm{a}}$ \\
\hline $20^{\circ} \mathrm{C}$ & $4.4 \pm 0.3^{\mathrm{b}}$ & $3.6 \pm 0.5^{\mathrm{a}}$ & $1.9 \pm 0.4^{\mathrm{b}}$ & $1.2 \pm 0.3^{\mathrm{b}}$ & $0.7 \pm 0.1^{b *}$ \\
\hline $30^{\circ} \mathrm{C}$ & $6.2 \pm 0.2^{\mathrm{c} *}$ & $4.6 \pm 0.4^{b *}$ & $1.1 \pm 0.2^{\mathrm{c} *}$ & $0.6 \pm 0.1^{b}$ & $0.6 \pm 0.1^{\mathrm{b}}$ \\
\hline
\end{tabular}

Different letters denote differences after temperature change

$P_{\text {sys }}$ mean systemic pressure, $P_{\text {pul }}$ mean pulmonary pressure, $V \mathrm{~s}$ total stroke volume, $V \mathrm{~s}_{\text {sys }}$ systemic stroke volume, $V \mathrm{~s}_{\text {pul }}$ pulmonary stroke volume

* Difference due to activity; bold values indicate differences due to vagotomy. Statistical significance was assigned as $P<0.05$ for all cases. For $P_{\text {sys }}$ and $P_{\text {pul }}$, sample sizes were $n=6$; for $V \mathrm{~s}, V \mathrm{~s}_{\text {sys }}$ and $V \mathrm{~s}_{\text {pul }}$, sample sizes were: intact and inactive, $n=10$; intact and active, $n=9$; vagotomized and inactive, $n=10$; vagotomized and active, $n=9$

\section{Effects of temperature on intact snakes}

The rise in $\mathrm{CO}$ with temperature of intact, inactive snakes was proportional to the elevation of $\mathrm{O}_{2}$ uptake reported by Leite et al. (2013) and almost exclusively achieved by increased $f_{\mathrm{H}}$ as in other squamates (Clark et al. 2005; Stinner 1987; Tucker 1966; Wood et al. 1977) and chelonians (Kinney et al. 1977; Krosniunas and Hicks 2003). The combination of altered autonomic tones and the direct effect of temperature on the cardiac pacemaker tissue may be the primary reason for the observed tachycardia (Lillywhite et al. 1999; Seebacher 2009). However, in contrast to other reptiles (Galli et al. 2004; Stecyk et al. 2004; Stinner 1987), $G_{\text {sys }}$ did not increase with temperature because of concomitant elevations of both $P_{\text {sys }}$ and $\dot{Q}_{\text {sys. }}$. The maintenance of R-L shunts at different temperatures indicates that resting metabolic rate changes with temperature observed in C. durissus (Leite et al. 2013) are unrelated to shunt patterns. Rather, $\mathrm{O}_{2}$ demand is probably matched by a combination of $\mathrm{CO}$ increase and adjustments in blood $\mathrm{O}_{2}$-carrying capacity, which is evidenced by the rise of arterial $P_{\mathrm{O}_{2}}$ and $\mathrm{HbO}_{2}$ saturation in C. durissus (Wang et al. 1998).

\section{Cardiovascular responses to activity in intact snakes}

Leite et al. (2013) demonstrated that 5 min of forced activity elevates $\mathrm{O}_{2}$ uptake four to sixfold at $30{ }^{\circ} \mathrm{C}$ in $C$. durissus. The present experiments show that $f_{\mathrm{H}}$ and $\mathrm{CO}$ increase 56 and $66 \%$ during a bout of activity, which implies that the arterial-venous (AV) $\mathrm{O}_{2}$ concentration difference was increased during activity as described in other reptiles (Clark et al. 2005; Frappell et al. 2002; Gleeson et al. 1980). Increased $G_{\text {pul }}$ during activity in all temperatures is probably a result from reduced vagal tone, which resulted in $\dot{Q}_{\text {pul }}$ and L-R shunt increase and is in agreement with previous studies of reptiles during exercise (Frappell et al. 2002; Hicks and Krosniunas 1996).

\section{Effect of left vagotomy in inactive snakes}

Cardiac shunts were related to the ratio between vascular conductances (Fig. 4a; Crossley et al. 1998; Galli et al. 2007; Hicks et al. 1996). Left vagotomy induced loss of control of $G_{\text {pul }}$ that resulted in elevated $\dot{Q}_{\text {pul }}$ and L-R shunts in inactive rattlesnakes at $15^{\circ} \mathrm{C}$, which suggests that 


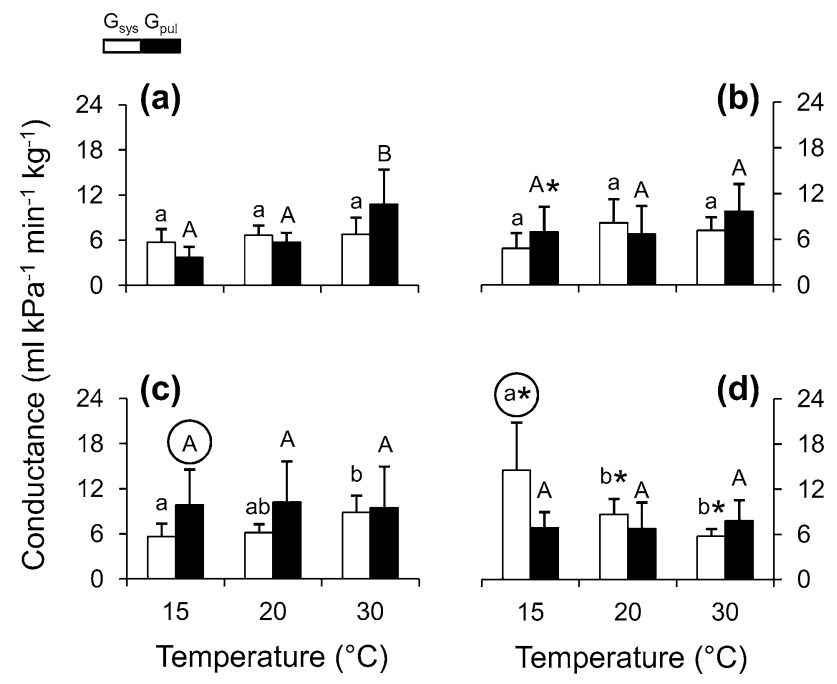

Fig. 2 Variation of systemic and pulmonary vascular conductances $\left(G_{\text {sys }}=\right.$ open bars; $G_{\text {pul }}=$ closed bars, respectively- $\mathrm{ml} \mathrm{kPa}^{-1}$ $\left.\min ^{-1} \mathrm{~kg}^{-1}\right)$ according to different temperatures $\left(15^{\circ} \mathrm{C}, 20{ }^{\circ} \mathrm{C}\right.$ and $30{ }^{\circ} \mathrm{C}$ ) in the experimental groups: a inactive and intact; $\mathbf{b}$ inactive and vagotomized; $\mathbf{c}$ active and intact; $\mathbf{d}$ vagotomized and active. Different small letters indicate differences due to temperature change in $G_{\text {sys}}$; different capital letters indicate differences due to temperature change in $G_{\mathrm{pul}}$; the ringed letter indicates a difference between inactive and active snakes; an asterisk indicates an effect of left vagotomy. Values are mean \pm SD. Statistical significance was $P<0.05$. Sample sizes were: intact and inactive, $n=16$; intact and active, $n=15$; vagotomized and inactive, $n=16$; vagotomized and active, $n=15$
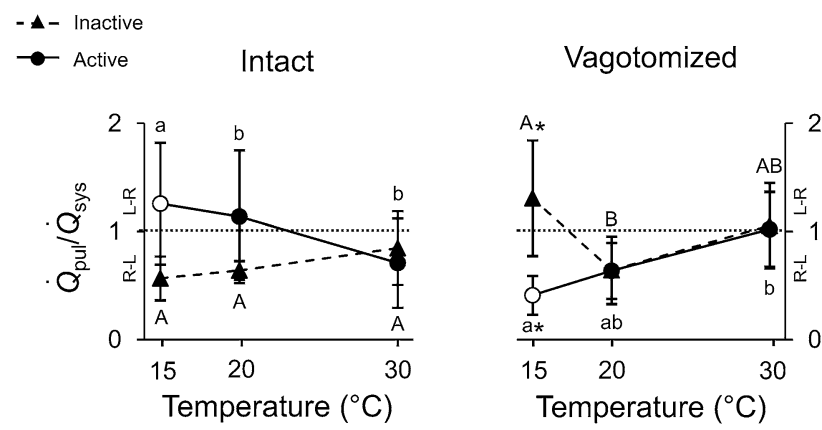

Fig. 3 Effects of temperature and activity in cardiac shunt direction $\left(\dot{Q}_{\text {pul }} / \dot{Q}_{\text {sys }}\right)$ on either intact or left-vagotomized snakes, when inactive (triangle) or during activity (circle). Different capital letters indicate differences due to temperature change within inactive groups; different small letters indicate differences due to temperature change within active groups; an asterisk indicates an effect of left vagotomy. Values are mean \pm SD. Statistical significance was $P<0.05$. Sample sizes were: intact and inactive, $n=10$; intact and active, $n=9$; vagotomized and inactive, $n=10$; vagotomized and active, $n=9$

increased vagal activity sustains the $\mathrm{R}-\mathrm{L}$ shunt at reduced temperatures. This finding confirms numerous reports outlining the importance of vagal tone in determining cardiac shunt direction in reptiles (Burggren 1977; Milsom et al.
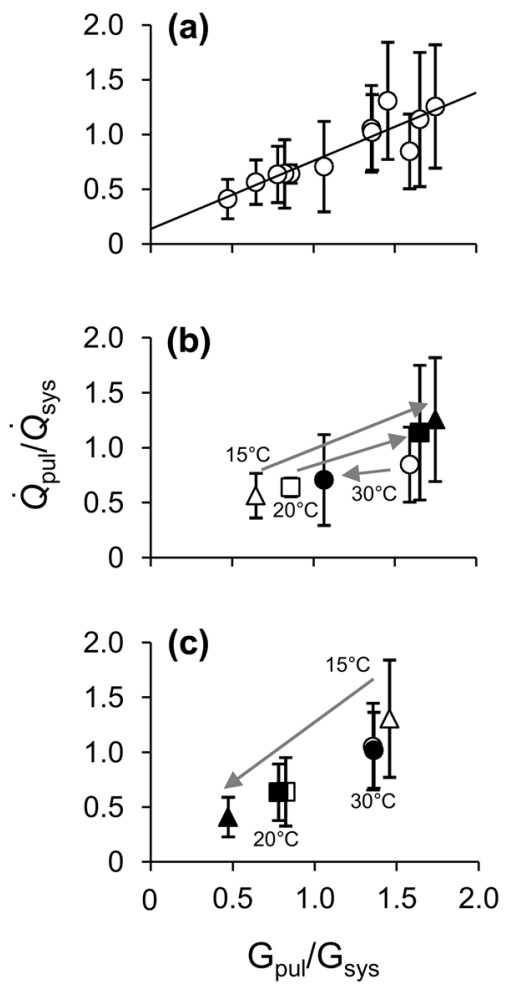

Fig. 4 a Positive regression between cardiac shunt direction $\left(\dot{Q}_{\text {pul }} / \dot{Q}_{\text {sys }}\right)$ and ratio of vascular conductances $\left(G_{\text {pul }} / G_{\text {sys }}\right)$ in the overall data set $\left(r^{2}=0.82 ; P<0.001\right)$. Variations in $\dot{Q}_{\text {pul }} / \dot{Q}_{\text {sys }}$ as a function of $G_{\text {pul }} / G_{\text {sys }}$ on either intact (b) or vagotomized (c) snakes at $15{ }^{\circ} \mathrm{C}$ (triangle), $20{ }^{\circ} \mathrm{C}$ (square) or $30{ }^{\circ} \mathrm{C}$ (circle). Open symbols represent inactive and closed symbols active snakes. Arrows represent the direction of the variation on cardiac shunts due to activity at a given temperature. Values are mean \pm SD. Sample sizes were: intact and inactive, $n=16$; intact and active, $n=15$; vagotomized and inactive, $n=16$; vagotomized and active, $n=15$

1977; Hicks 1994; Comeau and Hicks 1994; Hicks and Comeau 1994).

\section{Cardiovascular responses of left-vagotomized snakes to activity}

The pooled effects of activity and left vagotomy altered $\dot{Q}_{\text {sys }}, \mathrm{CO}, V \mathrm{~s}_{\text {sys }}, \dot{Q}_{\text {pul }} / \dot{Q}_{\text {sys }}$ and $G_{\text {sys }}$ when compared to active intact individuals. We speculate that the growing AV difference during activity and the inability to properly direct $\mathrm{O}_{2}$-rich blood to the systemic circulation led to a drastic regulation of $G_{\text {sys }}$ during activity, which raised far above $G_{\text {pul }}$ and allowed $\mathrm{O}_{2}$-rich blood to circulate at the systemic circuit. Hence, vagotomized rattlesnakes clearly displayed inverse shunt patterns in response to activity at $15{ }^{\circ} \mathrm{C}$.

The fact that oxygen consumption $\left(\dot{V} \mathrm{O}_{2}\right)$ was unaffected by left vagotomy during activity at 20 and $30{ }^{\circ} \mathrm{C}$ (Leite et al. 2013) is consistent with our observations that 
shunt patterns are not significantly different at these same temperatures (Fig. 3). Furthermore, similar shunt patterns displayed by both intact and vagotomized inactive snakes are in accordance with the observations of Wang and Hicks (2008) that found no effect of shunt patterns on both $\dot{V} \mathrm{O}_{2}$ and $\dot{V} \mathrm{CO}_{2}$ in $T$. scripta. Therefore, our data does not support the hypothesis that cardiac shunt patterns change according to metabolic demands on these temperatures. However, the observed L-R shunt at $15{ }^{\circ} \mathrm{C}$ during activity shows that at lower temperatures, shunt patterns do respond to metabolic changes. Unfortunately, Leite et al. (2013) do not report $\dot{V} \mathrm{O}_{2}$ during activity at $15^{\circ} \mathrm{C}$, so we cannot make comparisons with their data. Nevertheless, the $\mathrm{O}_{2}$-carrying capacity in $C$. durissus is markedly reduced at $15{ }^{\circ} \mathrm{C}$ compared to 25 and $35^{\circ} \mathrm{C}$ (Wang et al. 1998). In this scenario, increased L-R shunts could be tremendously beneficial to blood oxygenation during elevated metabolic demands due to activity by directing a higher portion of $\mathrm{CO}$ to the pulmonary circulation.

Although many mechanisms may influence cardiac shunts-humoral factors (Crossley et al. 2000; Galli et al. 2005a, b; Joyce and Wang 2014), adrenergic tone (Hicks 1994; Galli et al. 2007) and intrinsic differences between systemic and pulmonary vascular distensibilities (Kohl et al. 2013; Hillman et al. 2014)—left vagotomy completely inverted the shunt patterns observed at $15{ }^{\circ} \mathrm{C}$. This is in accordance with the observations of cholinergic control of R-L shunts in T. scripta (Hicks and Comeau 1994). Further evidence of vagal influence on shunt patterns may also include its effects on the direction of heart depolarization during lung ventilation (Burggren 1978). Based on the present data, it is clear that vagal regulation of pulmonary vascular tone is an essential active mechanism controlling cardiac shunt patterns in C. durissus.

Acknowledgments We thank the Butantan Institute for providing, and Carlinhos and Joniel for taking care of snakes used in this study; R Labouriau and JR Knaub for statistical help; JE Carvalho and LH Florindo for valued comments on previous versions of the manuscript. PB Dickinson, JM Osbourne and J Petrucci were great motivators throughout the study. This study was funded by the Fundação de Amparo à pesquisa do Estado de São Paulo and Conselho Nacional de Desenvolvimento Científico e Tecnológico through the Instituto Nacional de Ciência e Tecnologia em Fisiologia Comparada. RF received a stipend from Coordenação de Aperfeiçoamento de Pessoal de Ensino Superior through the Ciência sem Fronteiras programme, CACL had financial support from FAPESP, ASA from CNPq, EWT was supported both by FAPESP and by CNPq through the Ciência sem Fronteiras programme and TW was supported by the Danish Research Council.

\section{References}

Burggren WW (1977) The pulmonary circulation of the chelonian reptile: morphology, haemodynamics and pharmacology. J Comp Physiol B 116:303-323
Burggren WW (1978) Influence of intermittent breathing on ventricular depolarization patterns in chelonian reptiles. J Physiol 278:349-364

Burggren WW (1987) Form and function in reptilian circulations. Am Zool 27:5-19

Clark TD, Wang T, Butler PJ, Frappell PB (2005) Factorial scopes of cardio-metabolic variables remain constant with changes in body temperature in the varanid lizard, Varanus rosenbergi. Am J Physiol 288:R992-R997

Comeau SG, Hicks JW (1994) Regulation of central vascular blood flow in turtle. Am J Physiol 36:R569-R578

Crossley D, Altimiras J, Wang T (1998) Hypoxia elicits an increase in pulmonary vasculature resistance in anaesthetised turtles (Trachemys scripta). J Exp Biol 201:3367-3375

Crossley D, Wang T, Altimiras J (2000) Role of nitric oxide in the systemic and pulmonary circulation of anesthetized turtles (Trachemys scripta). J Exp Zool 286:683-689

Eme J, Gwalthney J, Blank JM, Owerkowicz T, Barron G, Hicks JW (2009) Surgical removal of right-to-left cardiac shunt in the American alligator (Alligator mississippiensis) causes ventricular enlargement but does not alter apnoea or metabolism during diving. J Exp Biol 212:3553-3563

Eme J, Gwalthney J, Owerkowicz T, Blank JM, Hicks JW (2010) Turning crocodilian hearts into bird hearts: growth rates are similar for alligators with and without right-to-left cardiac shunt. J Exp Biol 213:2673-2680

Filogonio R, Taylor EW, Carreira LBT, Leite GSPC, Abe AS, Leite CAC (2014) Systemic blood flow relations in conscious South American rattlesnakes. South Am J Herpetol 9:171-176

Frappell PB, Schultz T, Christian K (2002) Oxygen transfer during aerobic exercise in a varanid lizard Varanus mertensi is limited by the circulation. J Exp Biol 205:2725-2736

Galli G, Taylor EW, Wang T (2004) The cardiovascular responses of the freshwater turtle Trachemys scripta to warming and cooling. J Exp Biol 207:1471-1478

Galli G, Skovgaard N, Abe AS, Taylor EW, Wang T (2005a) The role of nitric oxide in the regulation of the systemic and pulmonary vasculature of the rattlesnake, Crotalus durissus terrificus. J Comp Physiol 175 B:201-208

Galli G, Skovgaard N, Abe AS, Taylor EW, Conlon JM, Wang T (2005b) Cardiovascular actions of rattlesnake bradykinin ([Val ${ }^{1}$, $\left.\mathrm{Thr}^{6}\right]$ bradykinin) in the anesthetized South American rattlesnake Crotalus durissus terrificus. Am J Physiol 288:R456-R465

Galli G, Skovgaard N, Abe AS, Taylor EW, Wang T (2007) The adrenergic regulation of the cardiovascular system in the South American rattlesnake, Crotalus durissus. Comp Biochem Phys 148 A:510-520

Gleeson TT, Mitchell GS, Bennett AF (1980) Cardiovascular responses to graded activity in the lizards Varanus and Iguana. Am J Physiol 239:R174-R179

Goodman LA (1969) On the exact variance of products. J Am Stat Assoc 55:708-713

Herman JK, Smatresk NJ (1999) Cardiorespiratory response to progressive hypoxia and hypercapnia in the turtle Trachemys scripta. J Exp Biol 202:3205-3213

Hicks JW (1994) Adrenergic and cholinergic regulation of intracardiac shunting. Physiol Zool 67:1325-1346

Hicks JW (2002) The evolutionary and physiological significance of cardiovascular shunting patterns in reptiles. News Physiol Sci $17: 241-245$

Hicks JW, Comeau SG (1994) Vagal regulation of intracardiac shunting in the turtle Pseudemys scripta. J Exp Biol 186:109-126

Hicks JW, Krosniunas E (1996) Physiological states and intracardiac shunting in non-crocodilian reptiles. Exp Biol Online 1:35-57

Hicks JW, Wang T (2012) The functional significance of the reptilian heart: new insights into an old question. In: Wang T, Sedmera D 
(eds) Ontogeny and phylogeny of the heart. Springer, New York, pp 207-227

Hicks JW, Ishimatsu A, Molli S, Erskin A, Heisler N (1996) The mechanism of cardiac shunting in reptiles: a new synthesis. J Exp Biol 199:1435-1446

Hillman SS, Hedrick MS, Kohl ZF (2014) Net cardiac shunts in anuran amphibians: physiology or physics? J Exp Biol 217:2844-2847

Jensen B, Abe AS, Andrade DV, Nyengaard JR, Wang T (2010) The heart of the South American rattlesnake, Crotalus durissus. J Morphol 271:1066-1077

Joyce W, Wang T (2014) Adenosinergic regulation of the cardiovascular system in the red-eared slider Trachemys scripta. Comp Biochem Physiol 174 A:18-22

Kempen GMP, Vliet LJ (2000) Mean and variance of ratio estimators used on fluorescence ratio imaging. Cytometry 39:300-305

Kinney JL, Matsuura DT, White FN (1977) Cardiorespiratory effects of temperature in the turtle, Pseudemys floridana. Respir Physiol 31:309-325

Kohl ZF, Hedrick MS, Hillman SS (2013) Separating the contributions of vascular anatomy and blood viscosity to peripheral resistance and the physiological implications of interspecific resistance variation in amphibians. J Comp Physiol 183 B:921-932

Krosniunas EH, Hicks JW (2003) Cardiac output and shunt during voluntary activity at different temperatures in the turtle, Trachemys scripta. Physiol Biochem Zool 76:679-694

Leite CAC, Taylor EW, Wang T, Abe AS, Andrade DOV (2013) Ablation of the ability to control the right-to-left cardiac shunt does not affect oxygen uptake, specific dynamic action or growth in the rattlesnake Crotalus durissus. J Exp Biol 216:1881-1889

Leite CAC, Wang T, Taylor EW, Abe AS, Leite GSPC, Andrade DOV (2014) Loss of the ability to control R-L shunt does not influence the metabolic responses to temperature change or long-term fasting in the South American rattlesnake, Crotalus durissus. Physiol Biochem Zool 87:568-575

Lillywhite HB, Zippel KC, Farrell AP (1999) Resting and maximal heart rates in ectothermic vertebrates. Comp Biochem Phys 124 A:369-382

Luckhardt AB, Carlson AJ (1921) Studies on the visceral sensory nervous system. VIII. On the presence of vasomotor fibers in the vagus nerve to the pulmonary vessels of the amphibian and the reptilian lung. Am J Physiol 56:72-112

Milsom WK, Langille BL, Jones DR (1977) Vagal control of pulmonary vascular resistance in the turtle Chrysemys scripta. Can J Zool 55:359-367
Seebacher F (2009) Responses to temperature variation: integration of thermoregulation and metabolism in vertebrates. J Exp Biol 212:2885-2891

Stecyk JAW, Overgaard J, Farrell AP, Wang T (2004) $\alpha$-Adrenergic regulation of systemic peripheral resistance and blood flow distribution in the turtle Trachemys scripta during anoxic submergence at $5{ }^{\circ} \mathrm{C}$ and $21^{\circ} \mathrm{C}$. J Exp Biol 207:269-283

Stinner JN (1987) Cardiovascular and metabolic responses to temperature in Coluber constrictor. Am J Physiol 253:R222-R227

Taylor EW, Andrade DV, Abe AS, Leite CAC, Wang T (2009) The unequal influences of the left and right vagi on the control of the heart and pulmonary artery in the rattlesnake, Crotalus durissus. J Exp Biol 212:145-151

Tucker VA (1966) Oxygen transport by the circulatory system of the green iguana (Iguana iguana) at different body temperatures. J Exp Biol 44:77-92

Wang T, Hicks JW (1996a) The interaction of pulmonary ventilation and the right-left shunt on arterial oxygen levels. J Exp Biol 199:2121-2129

Wang T, Hicks JW (1996b) Cardiorespiratory synchrony in turtles. J Exp Biol 199:1791-1800

Wang T, Hicks JW (2008) Changes in pulmonary blood flow do not affect gas exchange during intermittent ventilation in resting turtles. J Exp Biol 211:3759-3763

Wang T, Fernandes W, Abe AS (1993) Blood pH and $\mathrm{O}_{2}$ homeostasis upon $\mathrm{CO}_{2}$ anesthesia in the rattlesnake (Crotalus durissus). Snake 25:21-26

Wang T, Krosniunas E, Hicks JW (1997) The role of cardiac shunts in the regulation of arterial blood gases. Am Zool 37:12-22

Wang T, Abe AS, Glass ML (1998) Effects of temperature on lung and blood gases in the South American rattlesnake Crotalus durissus terrificus. Comp Biochem Phys 121 A:7-11

Wang T, Warburton S, Abe AS, Taylor EW (2001) Vagal control of heart rate and cardiac shunts in reptiles: relation to metabolic state. Exp Physiol 86:777-784

West NH, Butler PJ, Bevan RM (1992) Pulmonary blood flow at rest and during swimming in the green turtle, Chelonia mydas. Physiol Zool 65:287-310

Wood SC, Johansen K, Gatz RN (1977) Pulmonary blood flow, ventilation/perfusion ratio, and oxygen transport in a varanid lizard. Am J Physiol 2:R89-R93 